\title{
PERAMALAN PRODUK DOMESTIK BRUTO (PDB) INDUSTRI PENGOLAHAN NONMIGAS DI INDONESIA DENGAN MENGGUNAKAN METODE FUZZY TIME SERIES
}

\author{
Enka Rosita Dewi ${ }^{1, \text { a) }}$, Ibnu Hadi ${ }^{1, b)}$ \\ ${ }^{1}$ Program Studi Matematika, Fakultas Matematika dan Ilmu Pengetahuan Alam, Universitas Negeri Jakarta \\ Email: ${ }^{\text {a)enkarositadewi@gmail.com, }}{ }^{\text {b) }} \underline{\text { ibnu_hadi@unj.ac.id }}$
}

\begin{abstract}
Fuzzy Time Series is a time series forecasting method with fuzzy principle as the basis. The purpose of this paper is forecasting the GDP of non oil and gas processing industry in Indonesia start from third quarter of 2019 until fourth quarter of 2020 using Fuzzy Time Series Method modified by StevensonProter. The data of GDP non oil and gas processing industry constant prices of year 2010 from first quarter of 2010 until second quarter of 2019 is used in this paper. Fuzzy Time Series modified by Stevenson-Porter method can only forecast data to-t, so another classic forecasting method is needed to forecast data to $t+1$ until $t+n$. In this case, forecasting will be done in advance with ARIMA model $t$ obtain the data. The Fuzzy Time Series method on actual data plus forecast result from the ARIMA model have a smallr error rate MAPE is 0,133354 compared only by using ARIMA model is 0,862131 .
\end{abstract}

Keywords: Forecasting, Gross Domestic Product, Fuzzy Time Series, ARIMA

\begin{abstract}
Abstrak
Fuzzy Time Series merupakan metode peramalan data runtun waktu dengan prinsip fuzzy sebagai dasarnya. Pada penelitan ini, akan dilakukan penghitungan peramalan nilai PDB industri pengolahan nonmigas di Indonesia triwulan III tahun 2019 sampai dengan triwulan IV tahun 2020 dengan menggunakan metode Fuzzy Time Series hasil modifikasi Stevenson-Porter. Data yang digunakan pada makalah ini yaitu data PDB industri pengolahan nonmigas atas dasar harga konstan tahun 2010 mulai dari triwulan I tahun 2010 sampai dengan triwulan II tahun 2019. Metode Fuzzy Time Series Stevenson-Porter hanya dapat bisa meramalkan data ke-t, sehingga perlu metode peramalan klasik lain untuk meramalkan data ke- $t+1$ hingga $t+n$. Dalam hal ini akan dilakukan peramalan terlebih dahulu dengan model ARIMA untuk memperoleh dat tersebut. Penerapan metode Fuzzy Time Series pada data aktual ditambah data hasil peramalan dari model ARIMA menunjukkan nilai eror MAPE yang lebih kecil yaitu 0,133354 dibandingkan hanya dengan menggunakan model ARIMA yaitu 0,862131.
\end{abstract}

Kata-kata kunci: Peramalan, Produk Domestik Bruto, Fuzzy Time Series, ARIMA 


\section{PENDAHULUAN}

Salah satu indikator penting dalam mengukur kondisi suatu negara khususnya kondisi ekonomi dalam suatu periode tertentu adalah data Produk Domestik Bruto (PDB). Produk Domestik Bruto (PDB) didefinisikan sebagai jumlah total produk berupa barang dan jasa yang dihasilkan oleh unit produksi dalam batas wilayah suatu negara baik atas dasar harga berlaku maupun atas dasar harga konstan. PDB atas dasar harga berlaku menggambarkan nilai tambah barang dan jasa yang dihitung menggunakan harga pada tahun berjalan, sedangkan PDB atas dasar harga konstan menunjukkan nilai tambah barang dan jasa yang dihitung menggunakan harga yang berlaku pada satu tahun tertentu sebagai tahun dasar.

Kontribusi terbesar pada pembentukan PDB adalah industri pengolahan nonmigas. Sehingga, melalui gambaran umum PDB industri nonmigas diharapkan dapat mewakili kondisi ekonomi Indonesia masa kini dan untuk masa yang akan datang membutuhkan suatu proses yaitu proses peramalan. Data yang digunakan untuk peramalan ini adalah data historis PDB industri nonmigas. Data historis PDB industri nonmigas merupakan data berurutan yang berjarak sama yaitu dihitung tiap triwulan sehingga data PDB dapat disebut sebagai data time series. Dalam meramalkan menggunakan data time series, dibutuhkan teknik peramalan yang baik. Tujuan utama proses peramalan adalah mengurangi ketidakpastian dan membuat perkiraan lebih baik dari apa yang terjadi di masa mendatang. Untuk itu, diperlukan sistem peramalan yang tepat dan akurat agar lembaga pemerintahan mampu mengantisipasi dan membuat keputusan yang tepat pada kejadian yang akan datang. Dalam akumulasi data PDB ini tidak selalu dalam bentuk yang jelas.

Ketidakpastian keadaan suatu negara seperti pada saat hari-hari besar dan bencana alam dapat menjadi faktor yang memengaruhi ketidakpastian tersebut. Dengan adanya ketidakpastian tersebut, bilangan fuzzy menjadi alternatif yang sangat sesuai untuk menyatakan ketidakpastian tersebut. Metode peramalan dengan menggunakan bilangan fuzzy adalah salah satu metode yang memiliki tingkat keakuratan yang tinggi berdasarkan nilai eror yang mendekati $0 \%$. Peramalan dengan metode fuzzy untuk data time series dikenal sebagai fuzzy time series. Fuzzy time series pertama kali diusulkan oleh Song dan Chissom yang diterapkan dalam konsep logika fuzzy untuk mengembangkan dasar dari fuzzy time series (Song,1993). Sejak saat itu, banyak metode fuzzy time series yang diusulkan oleh peneliti lainnya seperti: fuzzy time series model markov chain (Sullivan, 1994), metode fuzzy time series baru dalam peramalan data penerimaan mahasiswa baru Universitas Alabama (Chen dan Hsu, 2004), pendekatan fuzzy metric untuk peramalan fuzzy time series (Jilani dkk, 2007), dan multipleatribut metode fuzzy time series (Cheng, 2008). Pada penelitian ini akan digunakan metode fuzzy time series modifikasi Meredith Stevenson dan John E. Porter (Stevenson, 2009) yaitu dengan model persentase perubahan untuk meramalkan data PDB industri pengolahn nonmigas triwulanan dan menghitung tingkat akurasi peramalan dengan kriteria nilai MAPE yang sangat kecil.

\section{METODE}

\section{Metode Fuzzy Time Series Stevenson-Porter}

Metode Fuzzy Time Series modifikasi Meredith Stevenson dan John E. Porter merupakan metode untuk meramalkan model data time series dimana membutuhkan input data $X=\left(X_{1}, X_{2}, X_{3}, \ldots, X_{n}\right)$ dan yang akan diramalkan adalah persentase perubahan antara 2 data yang berturutan, yaitu $D=\left(d_{1}, d_{2}, d_{3}, \ldots, d_{n}\right)$ kemudian dibuat Fuzzy Time Series $A_{i}, i=1,2, \ldots, k$ dengan menggunakan fungsi keanggotaan triangular. Fuzzy Time Series yang terbentuk akan diramalkan persentase perubahan datanya. Terdapat beberapa tahap dalam proses peramalan dengan metode ini yaitu tahap pembentukan model, fuzzifikasi, deffuzifikasi, tahap peramalan data, dan penghitungan kesalahan peramalan. 


\section{Fuzzifikasi}

Tahap ini menentukan nilai keanggotaan pada masing-masing himpunan fuzzy dari data historis, dengan nilai keanggotaan 0 sampai 1 . Nilai keanggotaan ini diperoleh dari fungsi keanggotaan yang telah dibuat sebelumnya. Selanjutnya mengubah besaran tegas menjadi besaran fuzzy, himpunan fuzzy yang akan digunakan untuk tahap defuzzifikasi sebelumnya dilakukan pencarian nilai tengah dengan menggunakan rumus sebagai berikut:

$$
a_{t}=\frac{L L i+U L i}{2}
$$

dengan $L L i$ merupakan batas bawah interval ke-I dan $U L i$ adalah batas atas interval ke- $i$

\section{Defuzzifikasi}

Defuzzifikasi adalah cara untuk memperoleh nilai tegas (crisp) dari himpunan fuzzy. Defuzzifikasi data menggunakan rumus berikut.

$$
t_{j}=\left\{\begin{array}{cl}
\frac{1.5}{\frac{1}{\alpha_{1}}+\frac{0.5}{\alpha_{2}}} & , \text { untuk } j=1 \\
\frac{2}{0.5}+\frac{1}{\alpha_{j-1}+\frac{1.5}{\alpha_{j}}} & , \text { untuk } 2 \leq j \leq n-1 \\
\frac{1.5}{0.5} \frac{1}{\alpha_{n-1}}+\frac{1}{\alpha_{n}} & , \text { untuk } j=n
\end{array}\right.
$$

dengan $a_{j-1}, a_{j}, a_{j+1}$ adalah titik tengah interval fuzzy $X_{j-1}, X_{j}, X_{j+1}$ dan $t_{j}$ merupakan peramalan persentase perubahan data dari tahun ke tahun.

Menentukan nilai data berdasarkan hasil ramalan $t_{j} \rightarrow X_{t}$ dengan $X_{t}$ adalah persentase perubahan data hasil peramalan dengan menggunakan rumus sebagai berikut.

$$
F_{i}=\left(\frac{t_{j}}{100} \times X_{t-1}\right)+X_{t-1}
$$

\section{Pengukuran Kesalahan Peramalan}

Kesalahan peramalan (error) merupakan ukuran seberapa baik kinerja suatu model peramalan yang digunakan dengan membandingkan nilai hasil peramalan dari model tersebut dengan data aktual. Semakin kecil nilai kesalahan peramalan maka dapat dikatakan metode peramalan yang digunakan semakin baik. Alternatif untuk mengukur kesalahan dapat dilakukan dengan menghitung Mean Square Error (MSE) dan Mean Absolute Percentage Error (MAPE).

$$
M S E=\frac{1}{n} \sum_{i=1}^{n}\left(X_{i}-F_{i}\right)^{2}
$$


$M A P E=\frac{\sum\left|\frac{\left(X_{i}-F_{i}\right)}{X_{i}}\right| \times 100 \%}{n}$

\section{Sumber Data}

Data diperoleh dari Kementrian Perindustrian divisi Pusat Data dan Informasi mengenai data PDB Industri Pengolahan Nonmigas Indonesia tahun 2010 - 2019

\section{Tahapan Penelitian}

Dari 38 data akan dibuat model prediksi dengan menggunakan metode fuzzy time series yang diajukan oleh Meredith Stevenson dan John E. Porter dengan langkah sebagai berikut:

1. Transformasi data kedalam bentuk persentase dengan menggunakan rumus

$$
d_{i}=\frac{t_{j}-t_{j-1}}{t_{j-1}} \times 100 \%
$$

2. Mendefinisikan himpunan semesta $U=\left[D_{\min } ; D_{\max }\right]$ membaginya menjadi interval-interval $U_{1}, U_{2}, U_{3}, \ldots, U_{n}$ dengan panjang yang sama dengan menggunakan Kaidah Sturges.

3. Menemukan sebaran perubahan persentase pertumbuhan PDB dari triwulan ke triwulan berikutnya dengan mensortir data ke dalam interval yang sudah ditentukan.

4. Mendefinisikan masing-masing himpunan fuzzy berdasarkan interval yang sudah dibagi-bagi dan memfuzzikan data historis pertumbuhan PDB.

5. Defuzzifikasi data fuzzy dengan menggunakan formula peramalan fuzzy time series hasil modifikasi Meredith Stevenson dan John E. Porter.

6. Mengubah persentase hasil peramalan kedalam bentuk angka kembali dan menentukan nilai Mean Absolute Percentage Error (MAPE) dan Mean Square Error (MSE) untuk melihat tingkat keakuratan metode peramalan.

\section{HASIL DAN PEMBAHASAN}

\section{Tahap Pembentukan Model}

Peramalan dengan metode fuzzy time series hanya dapat meramalkan data ke- $t$, sehingga apabila ingin meramalkan data ke $t+1, t+2$, sampai $t+n$ dibutuhkan metode peramalan klasik terdahulu. Peramalan yang dilakukan untuk mengetahui nilai $x_{t+1}$ sampai $x_{t+6}$ digunakan model peramalan klasik yaitu model ARIMA. Model ARIMA ini digunakan karena data mengandung trend naik seperti pada plot data berikut. 


\section{Data Nilai PDB Industri Pengolahan Non Migas Indonesia}

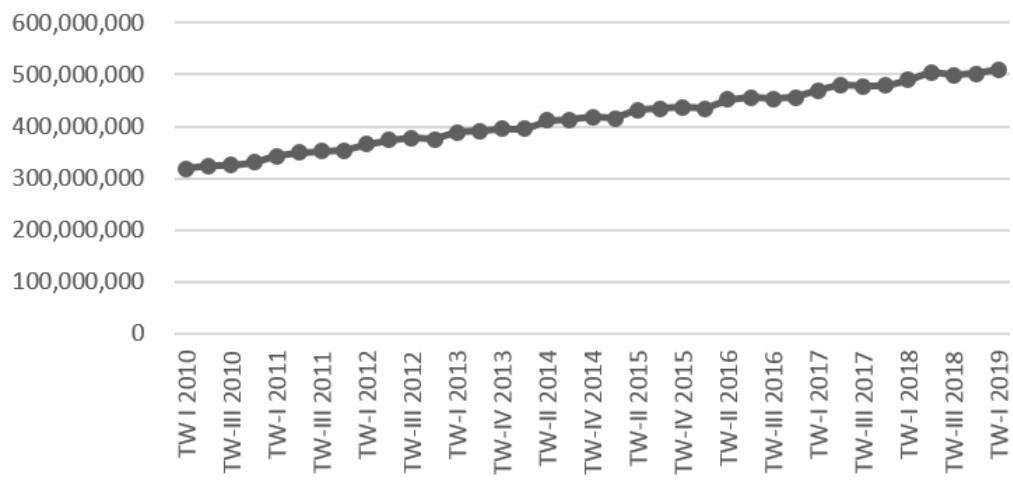

GAMBAR 1. Plot Data PDB Industri Pengolahan Nonmigas di Indonesia

Setelah dilakukan analisis model ARIMA dari data tersebut, didapatkan model yaitu model ARIMA(3,2,1). Nilai peramalan yang didapatkan untuk $x_{t+1}$ yaitu periode triwulan III tahun 2019 sampai $x_{t+6}$ periode triwulan IV tahun 2020 dapat dilihat pada Tabel 3 kolom 2 dengan nilai kesalahan peramalan MSE sebesar 27,518,400,000,000 dan nilai kesalahan peramalan MAPE sebesar 0.862131. Kemudian dari 38 data akan dibuat model prediksi. Untuk tahap pembentukan model terlebih dahulu dilakukan transformasi data menjadi persentase perubahan data dengan rumus transformasi data. Selanjutnya adalah menentukan himpunan semesta $U=\left[D_{\min } ; D_{\max }\right]$. Untuk mendefinisikan himpunan semesta maka terlebih dahulu mencari banyaknya selang interval. Dalam menentukan banyaknya selang yang akan digunakan rumus Sturges.

$$
K_{\text {interval }}=1+3.322 \log \left(N_{\text {data }}\right)
$$

didapat banyaknya selang berjumlah 6 selang interval. Dari seluruh data yang ada dapat dinyatakan himpunan Semesta $U=[-1.07 \% ; 3.98 \%]$, dengan lebar masing-masing interval setelah dibagi 6 interval didapat sebagai berikut.

$$
\begin{aligned}
& U_{1}=[-1.07 \% ;-0.23 \%], U_{2}=[-0.23 \% ; 0.61 \%], U_{3}=[0.61 \% ; 1.45 \%] \\
& U_{4}=[1.45 \% ; 2.29 \%], U_{5}=[2.29 \% ; 3.13 \%], U_{6}=[3.13 \% ; 3.98 \%]
\end{aligned}
$$

Kemudian masing-masing interval ditentukan frekuensinya dan ditentukan jumlah subinterval dengan memberi peringkat sesuai jumlah data dimana peringkat terbesar dimulai dari interval dengan jumlah data terbesar sampai terkecil.

TABEL 1. Frekuensi Kepadatan Data Berdasarkan Distribusi Perubahan Persentase

\begin{tabular}{cccc}
\hline Selang ke- & Interval & Jumlah Data & Jumlah Sub Interval \\
\hline 1 & {$[-1.07 \% ;-0.23 \%]$} & 6 & 3 \\
2 & {$[-0.23 \% ; 0.61 \%]$} & 8 & 4 \\
3 & {$[0.61 \% ; 1.45 \%]$} & 6 & 3 \\
4 & {$[1.455 ; 2.29 \%]$} & 4 & 1 \\
5 & {$[2.29 \% ; 3.13 \%]$} & 5 & 2 \\
6 & {$[3.13 \% ; 3.98 \%]$} & 6 & 3 \\
\hline
\end{tabular}

Terdapat 6 peringkat yang dihasilkan, untuk interval peringkat ke-2 dibagi menjadi 2 subinterval yang sama besar, interval dengan peringkat ke-3 dibagi menjadi 3 subinterval yang sama besar, demikian seterusnya hingga interval peringkat ke-6 dibagi menjadi 6 subinterval yang sama besar. Sehingga akhirnya subinterval yang terbentuk adalah 16 subinterval. 


\section{Fuzzifikasi dan Defuzzifikasi}

Dari 16 subinterval tersebut akan menjadi domain untuk himpunan fuzzy $A_{i}$ yang terbentuk dengan fungsi keanggotaan triangular. Kemudian cari titik tengah pada interval yang diperoleh untuk mencari nilai prediksi persentase perubahan seperti yang terlihat pada Tabel 2. Selanjutnya adalah deffuzifikasi data fuzzy dengan menggunakan persamaan (2) untuk mengetahui nilai peramalan persentase perubahan data $t_{j}$. Hasilnya dapat dilihat pada Tabel 2 .

TABEL 2. Interval Fuzzy Menggunakan Kepadatan Frekuensi Berdasarkan Pembagian

\begin{tabular}{cccccc}
\hline $\begin{array}{c}\text { Himpunan } \\
\text { Fuzzy }\end{array}$ & Interval & $\begin{array}{c}\text { Nilai } \\
\text { Tengah }\end{array}$ & $\begin{array}{c}\text { Lebar } \\
\text { Interval }\end{array}$ & Linguistik & $\mathbf{t}_{\mathbf{j}}$ \\
\hline $\mathrm{A}_{1}$ & {$[-1.07 ;-0.79]$} & -0.93 & 0.28 & $\mathrm{a}_{1}$ & -0.81 \\
$\mathrm{~A}_{2}$ & {$[-0.79 ;-0.51]$} & -0.65 & 0.28 & $\mathrm{a}_{2}$ & -0.58 \\
$\mathrm{~A}_{3}$ & {$[-0.51 ;-0.23]$} & -0.37 & 0.28 & $\mathrm{a}_{3}$ & -0.27 \\
$\mathrm{~A}_{4}$ & {$[-0.23 ;-0.02]$} & -0.13 & 0.21 & $\mathrm{a}_{4}$ & -0.58 \\
$\mathrm{~A}_{5}$ & {$[-0.02 ; 0.19]$} & 0.09 & 0.21 & $\mathrm{a}_{5}$ & 0.21 \\
$\mathrm{~A}_{6}$ & {$[0.19 ; 0.40]$} & 0.30 & 0.21 & $\mathrm{a}_{6}$ & 0.19 \\
$\mathrm{~A}_{7}$ & {$[0.40 ; 0.61]$} & 0.51 & 0.21 & $\mathrm{a}_{7}$ & 0.46 \\
$\mathrm{~A}_{8}$ & {$[0.61 ; 0.89]$} & 0.75 & 0.28 & $\mathrm{a}_{8}$ & 0.71 \\
$\mathrm{~A}_{9}$ & {$[0.89 ; 1.17]$} & 1.03 & 0.28 & $\mathrm{a}_{9}$ & 0.99 \\
$\mathrm{~A}_{10}$ & {$[1.17 ; 1.45]$} & 1.31 & 0.28 & $\mathrm{a}_{10}$ & 1.32 \\
$\mathrm{~A}_{11}$ & {$[1.45 ; 2.29]$} & 1.87 & 0.84 & $\mathrm{a}_{11}$ & 1.79 \\
$\mathrm{~A}_{12}$ & {$[2.29 ; 2.71]$} & 2.50 & 0.42 & $\mathrm{a}_{12}$ & 2.38 \\
$\mathrm{~A}_{13}$ & {$[2.71 ; 3.13]$} & 2.92 & 0.42 & $\mathrm{a}_{13}$ & 2.88 \\
$\mathrm{~A}_{14}$ & {$[3.13 ; 3.41]$} & 3.27 & 0.28 & $\mathrm{a}_{14}$ & 3.24 \\
$\mathrm{~A}_{15}$ & {$[3.41 ; 3.69]$} & 3.55 & 0.28 & $\mathrm{a}_{15}$ & 3.54 \\
$\mathrm{~A}_{16}$ & {$[3.69 ; 3.98]$} & 3.84 & 0.28 & $\mathrm{a}_{16}$ & 3.74 \\
\hline
\end{tabular}

\section{Peramalan}

Selanjutnya untuk mencari nilai peramalan persentase perubahan data $\left(t_{j}\right)$ dapat menggunakan persamaan (2) dan hasil yang diperoleh seperti pada Tabel 3 kolom 5. Apabila semua nilai prediksi persentase perubahan data telah diperoleh, maka selanjutnya adalah meramalkan nilai data peramalan ke-i $\left(F_{i}\right)$ menggunakan nilai prediksi persentase perubahan data $\left(t_{j}\right)$ dengan menggunakan persamaan (3).

Untuk peramalan ke $t+1, t+2$, sampai dengan $t+6$ digunakan model pendahulu yaitu model peramalan klasik ARIMA(3,2,1). Hasil nilai peramalan $F_{i}$ dapat dilihat pada Tabel 3 kolom 6 . Kemudian dilakukan penghitungan nilai kesalahan peramalan error dengan MSE dan MAPE dengan persaman (4) dan (5). Didapat hasil MSE sebesar 532,843,949,117 dan MAPE sebesar 0.133354.

TABEL 3. Hasil Peramalan

\begin{tabular}{lccccc}
\hline Periode & $X_{t}$ & $d_{i}$ & $A_{i}$ & $t_{j}$ & $F_{i}$ \\
\hline TW-I 2010 & $311,629,446$ & - & - & - & - \\
TW -II 2010 & $318,492,196$ & 2.20 & $\mathrm{~A}_{11}$ & 1.79 & $317,207,613$ \\
TW-III 2010 & $324,139,701$ & 1.77 & $\mathrm{~A}_{11}$ & 1.79 & $324,193,206$ \\
TW-IV 2010 & $324,677,261$ & 0.17 & $\mathrm{~A}_{5}$ & 0.21 & $324,820,394$ \\
TW-I 2011 & $330,619,228$ & 1.83 & $\mathrm{~A}_{11}$ & 1.79 & $330,488,984$ \\
TW-II 2011 & $343,015,010$ & 3.75 & $\mathrm{~A}_{16}$ & 3.74 & $342,984,387$ \\
TW-III 2011 & $348,918,163$ & 1.72 & $\mathrm{~A}_{11}$ & 1.79 & $349,154,978$ \\
TW-IV 2011 & $351,847,100$ & 0.84 & $\mathrm{~A}_{8}$ & 0.71 & $351,395,482$ \\
TW-I 2012 & $353,070,739$ & 0.35 & $\mathrm{~A}_{6}$ & 0.19 & $352,515,610$ \\
\hline
\end{tabular}




\begin{tabular}{|c|c|c|c|c|c|}
\hline TW-II 2012 & $365,321,815$ & 3.47 & $\mathrm{~A}_{15}$ & 3.54 & $365,569,444$ \\
\hline TW-III 2012 & $374,182,868$ & 2.43 & $\mathrm{~A}_{12}$ & 2.38 & $374,016,474$ \\
\hline TW-IV 2012 & $377,755,985$ & 0.95 & $\mathrm{~A}_{9}$ & 0.99 & $377,887,278$ \\
\hline TW-I 2013 & $374,579,971$ & -0.84 & $\mathrm{~A}_{1}$ & -0.81 & $374,696,162$ \\
\hline TW-II 2013 & $389,208,894$ & 3.91 & $\mathrm{~A}_{16}$ & 3.74 & $388,589,262$ \\
\hline TW-IV 2013 & $390,915,185$ & 0.44 & $\mathrm{~A}_{7}$ & 0.46 & $390,999,255$ \\
\hline TW-I 2014 & $395,807,904$ & 1.25 & $\mathrm{~A}_{10}$ & 1.32 & $396,075,266$ \\
\hline TW-II 2014 & $395,223,351$ & -0.15 & $\mathrm{~A}_{4}$ & -0.58 & $393,512,218$ \\
\hline TW-III 2014 & $410,970,557$ & 3.98 & $\mathrm{~A}_{16}$ & 3.74 & $410,004,704$ \\
\hline TW-IV 2014 & $413,314,868$ & 0.57 & $\mathrm{~A}_{7}$ & 0.46 & $412,861,022$ \\
\hline TW-I 2015 & $417,997,146$ & 1.13 & $\mathrm{~A}_{9}$ & 0.99 & $417,406,685$ \\
\hline TW-II 2015 & $416,017,208$ & -0.47 & $\mathrm{~A}_{3}$ & -0.27 & $416,868,554$ \\
\hline TW-III 2015 & $432,438,022$ & 3.95 & $\mathrm{~A}_{16}$ & 3.74 & $431,576,252$ \\
\hline TW-IV 2015 & $435,130,741$ & 0.62 & $\mathrm{~A}_{8}$ & 0.71 & $435,508,332$ \\
\hline TW-I 2016 & $436,635,057$ & 0.35 & $\mathrm{~A}_{6}$ & 0.19 & $435,957,490$ \\
\hline TW-II 2016 & $434,797,850$ & -0.42 & $\mathrm{~A}_{3}$ & -0.27 & $435,456,143$ \\
\hline TW-III 2016 & $452,072,247$ & 3.97 & $\mathrm{~A}_{16}$ & 3.74 & $451,059,290$ \\
\hline TW-III 2016 & $455,899,448$ & 0.85 & $\mathrm{~A}_{8}$ & 0.71 & $455,281,959$ \\
\hline TW-IV 2016 & $453,715,234$ & -0.48 & $\mathrm{~A}_{3}$ & -0.27 & $454,668,520$ \\
\hline TW-I 2017 & $455,683,475$ & 0.43 & $\mathrm{~A}_{7}$ & 0.46 & $455,802,324$ \\
\hline TW-II 2017 & $469,833,082$ & 3.11 & $\mathrm{~A}_{13}$ & 2.88 & $468,807,159$ \\
\hline TW-III 2017 & $480,955,533$ & 2.37 & $\mathrm{~A}_{12}$ & 2.38 & $481,015,110$ \\
\hline TW-IV 2017 & $477,144,501$ & -0.79 & $\mathrm{~A}_{2}$ & -0.58 & $478,165,991$ \\
\hline TW-I 2018 & $478,835,877$ & 0.35 & $\mathrm{~A}_{6}$ & 0.19 & $478,051,076$ \\
\hline TW-II 2018 & $489,908,014$ & 2.31 & $\mathrm{~A}_{12}$ & 2.38 & $490,232,171$ \\
\hline TW-III 2018 & $505,100,800$ & 3.10 & $\mathrm{~A}_{13}$ & 2.88 & $504,017,364$ \\
\hline TW-IV 2018 & $499,691,601$ & -1.07 & $\mathrm{~A}_{1}$ & -0.81 & $501,009,484$ \\
\hline TW-I 2019 & $501,807,339$ & 0.42 & $\mathrm{~A}_{7}$ & 0.46 & $501,990,182$ \\
\hline TW-II 2019 & $509,382,056$ & 1.51 & $\mathrm{~A}_{11}$ & 1.79 & $510,789,690$ \\
\hline TW-III 2019 & $525,673,980$ & 3.20 & $\mathbf{A}_{14}$ & 3.24 & $\mathbf{5 2 5 , 8 8 6 , 0 3 5}$ \\
\hline TW-IV 2019 & $521,554,449$ & -0.78 & $\mathbf{A}_{2}$ & -0.58 & $522,625,071$ \\
\hline TW-I 2020 & $522,266,475$ & 0.14 & A5 & 0.21 & $522,649,714$ \\
\hline TW-II 2020 & $\mathbf{5 2 8 , 9 2 4 , 5 9 5}$ & 1.27 & $\mathbf{A}_{10}$ & 1.32 & $529,160,393$ \\
\hline TW-III 2020 & $545,660,411$ & 3.16 & $\mathbf{A}_{14}$ & 3.24 & $546,061,751$ \\
\hline TW-IV 2020 & $542,953,639$ & -0.50 & $\mathbf{A}_{3}$ & -0.27 & $544,187,128$ \\
\hline
\end{tabular}

keterangan:

$X_{t}=$ data periode ke- $\mathrm{t}$

$d_{i}=$ persentase perubahan data

$A_{i}=$ himpunan fuzzy

$t_{j}=$ peramalan persentase perubahan data

$F_{i}=$ nilai ramalan data ke-i 


\section{KESIMPULAN DAN SARAN}

\section{Kesimpulan}

Metode Fuzzy Time Series Stevenson-Porter hanya bisa meramalkan data ke-t, sehingga digunakan model klasik ARIMA untuk meramalkan data ke- $t+1$ sampa $t+6$. Dari model klasik ARIMA didapatkan MAPE sebesar 0.862131 dan MSE sebesar 27,518,400,000,000. Dari metode Fuzzy Time Series didapatkan MAPE sebesar 0.133354 dan MSE sebesar 532,843,949,117. Oleh karena itu, metode peramalan fuzzy time series terbukti menjadi metode yang cocok dalam mengatasi ketidakpastian dengan mengubah kedalam bilangan fuzzy dan memberikan hasil peramalan yang cukup baik dan akurat dilihat dari nilai MAPE dan MSE nya yang lebih kecil dari model ARIMA dan mendekati $0 \%$.

Dengan menerapkan metode fuzzy time series pada masalah peramalan diperoleh hasil peramalan nilai PDB Industri Pengolahan Nonmigas periode triwulan III tahun 2019, triwulan IV tahun 2019, sampai dengan triwulan IV tahun 2020 berturut-turut adalah 525,886,035 juta Rupiah, 522,625,071 juta Rupiah, 522,649,714 juta Rupiah, 529,160,393 juta rupiah, 546,061,751 juta rupiah, 544,187,128 juta rupiah. Hasil peramalan dapat dilihat mengalami kenaikan dan penurunan pada periode tertentu. Hal ini dapat menjadi gambaran awal institusi pemerintahan dalam mengkaji dan mengatur melalui kebijakan-kebijakan agar seluruh komponen PDB mendukung pertumbuhan ekonomi negara Indonesia di masa mendatang.

\section{Saran}

Hal yang disarankan untuk peneliti selanjutnya adalah dapat menggunakan metode peramalan klasik seperti Double Exponential Smoothing Holt dan menggunakan metode Fuzzy Time Series modifikasi yang lain seperti modifikasi Chen sebagai perbandingan.

\section{UCAPAN TERIMA KASIH}

Terima kasih kepada bidang Basis Data Pusat Data Informasi Kementrian Perindustrian atas ketersediaan data dalam penelitian ini.

\section{REFERENSI}

Azmiyati, Sarah. (2015) 'Peramalan Jumlah TBS Kelapa Sawit Dengan Metode Fuzzy Time Series', Jurnal PASTI, 8.

Chen, S. M. (1996) 'Forecasting enrollments based on fuzzy time series', Fuzzy Sets and Systems, 81(3), pp.311-319.

Hasbiollah, M. and Hakim, R.B. (2015) 'Peramalan Konsumsi Gas Indonesia Menggunakan Algoritma Fuzzy Time Series Stevenson Porter', Seminar Nasional Matematika dan Pendidikan Matematika, pp. 508-518.

Nurmalitasari. (2014) 'Peramalan Jumlah Pendaftar Calon Mahasiswa STMIK Duta Bangsa Menggunakan Metode Fuzzy Invariant Fuzzy Time Series', DutaCom Journal, 8(1).

Puspitasari, E., Linawati, L. and Parhusip, H.A. (2012) 'Peramalan Persentase Perubahan Data Indeks Harga Saham Gabungan (IHSG) dengan Fuzzy Time Series’, Prosiding Seminar Nasional Sains dan Pendidikan Sains VII UKSW, pp. 223-229.

Song, Q. and Chissom, B.S. (1994) 'Forecasting enrollments with fuzzy time series-Part II. Fuzzy sets and systems', 62(1), pp.1-8.

Stevenson, M. dan J. E. Porter (2009) 'Fuzzy time series forecasting using percentage change as the universe of discourse', Proceedings of World Academy of Science, Engineering and Technology, 55, pp.154- 157. 
Wanayasa, I.G.N.A,, Kencana, I,P.E.N. and Nilakusumawati, D.P.E. (2012) 'Peramalan Produk Domestik Regional Bruto (PDRB) Provinsi Bali deengan Menggunakan Metode Fuzzy Time Series', E-Jurnal Matematika, 1, pp.12-19. 